\title{
Analisis Nilai Pendidikan Karakter dalam Kumpulan Dongeng Suku Mbojo
}

\author{
Arif Bulan1, Hasan² \\ ${ }^{1}$ Dosen Program Studi Pendidikan Bahasa Inggris, STKIP Yapis Dompu \\ ${ }^{2}$ Dosen Program Studi Pendidikan Jasmani Kesehatan dan Rekreasi, STKIP Yapis Dompu \\ E-mail:arifbulan1@gmail.com
}

Article History: Received: 2020-09-14 || Revised: 2020-10-02 || Published: 2020-10-26

Sejarah Artikel : Diterima: 2020-09-14 || Direvisi: 2020-10-02 || Dipublikasi: 2020-10-26

\begin{abstract}
As a cultural product from a region, fairy tales have many values in it. This study aimed to describe the values of character education contained in the fairy tales of the Mbojo tribe. The research method used in this research was descriptive qualitative method. The research data was taken from the book "A collection of tales of the Mbojo tribe: as teaching materials for Indonesian in Elementary Schools" published by the publisher Nathan Indonesia 2020. The data needed in the study were collected through careful reading of the elements of fairy tales contained in the book. The technique used in research is note-taking techniques. The data analysis technique used in this study was to use content analysis techniques. The results of this study indicate that there were five values of character education contained in the book a collection of tales of the Mbojo tribe, including: (1) social care; (2) justice; (3) responsibility; (4) cooperation; (5) respect the opinions of others.
\end{abstract}

Keywords: Analysis, Fairy tales, Character, Educational values.

\begin{abstract}
Abstrak
Sebagai produk budaya suatu dari daerah, dongeng memiliki banyak nilai yang terkandung di dalamnya.Penelitian ini bertujuan untuk mendeskripsikan nilai-nilai pendidikan karakter yang termuat dalam cerita rakyat suku Mbojo. Metode penelitian yang digunakan dala penelitian ini yaitu metode deskriptif kualitatif. Data penelitian diambil dari buku "kumpulan dongeng suku Mbojo: sebagai bahan ajar bahasa Indonesia di Sekolah Dasar" yang diterbitkan oleh penerbit Nathan Indonesia 2020. Data-data yang dibutuhkan dalam penelitian dikumpulkan melalui membaca secara cermat unsur-unsur dongeng yang termuat dalam buku. Teknik yang digunanakan dalam penelitian teknik catat. Teknik analisis data yang dilakukan dalam penelitian ini yaitu menggunakan teknik analisis isi (content analysis). Hasil penelitian ini menunjukan bahwa terdapat lima nilai pendidikan karakter yang termuat dalam buku kumpulan dongeng suku Mbojo di antaranya: (1) peduli sosial; (2) keadilan; (3) tanggung jawab; (4) kerjasama; (5) menghargai pendapat orang lain.
\end{abstract}

Kata kunci: Analisis, Dongeng, Karakter, Nilai Pendidikan.

\section{PENDAHULUAN}

Dalam kegiatan studi litaratur (baik empiris maupun teoritis), peneliti menelusui berbagai literatur yang memiliki keterkaitan erat dengan tema penelitian ini di antaranya nilai pendidikan karakter dalam dongeng. Ada beberapa catatan penting yang peneliti temukan dalam studi literatur ini dengan memetakannya dalam dua konsep yaitu konsep dongeng dan konsep nilai pendidikan karakter. Konsep ini akan peneliti uraikan hingga menjadi latar belakang masalah yang mampu menjelaskan fenomena yang akan ditiliti. Dongeng ialah bagian dari dunia sastra. Lebih spesifik lagi sastra anak. Sastra anak memiliki beberpa genre seperti realisme, fiksi, fantasi, puisi, nonfiksi dan sastra tradisional. Dongeng masuk pada sastra tradisional jika dilihat dari sudut pandang penyampaiannya karena memang dongeng diwariskan secara turun temurun berbasis lisan. 
Terlepas dari itu, Lukens (2003) menegaskan bahwa sastra harus mampu menghadirkan kesenangan dan pemahaman tentang kehidupan. Pemahaman hadir dari eksplorasi berbagai bentuk kehidupan, rahasia kehidupan, penemuan dan pengungkapan berbagai macam karakter manusia (Nurgiyantoro, 2016). Selain itu, Nurgiyantoro (2016: 3) menambahkan bahwa sastra mengahdirkan cerita yang penuh makna dalam memberikan cerita yang menarik dan imajinatif sehingga dapat membawa pembaca pada daya fantasi.

Lahir dari produk budaya, dongeng seringkali disamakan dengan cerita rakyat. Nurgiyantoro (2016) menyebutkan bahwa dongeng merupakan salah satu cerita rakyat. Dulay dalam (Setiawan, Suwandi and Slamet, 2017) menyebutkan bahwa cerita rakyat adalah budaya yang telah melekat pada kelompok masyarakat. Begitupun dongeng, ia adalah budaya yang melekat pada kelompok masyarakat tertentu. Dongeng lahir dari tradisi tutur nenek moyang hingga turun pada anak cucu. Siklus penurunan dongeng pada genegrasi ke generasi sampai saat ini didominasi oleh tradisi tutur. Sehingga tradisi ini dikatakan sebagai tradisi yang turun temurun, Tradisi dongeng sudah sejak lama dilakukan oleh masyarakat suku Mbojo. Dongeng-dongeng yang ada pada suku mbojo masih berjenis klasik (sastra tradisional). Dongeng jenis ini biasanya dongeng yang sejak lama ada dan belum diubah oleh pengarang dengan tujuan kesengajaan atau kesenangan. Sampai saat ini peneliti belum menemukan dongeng moderen suku Mbojo yang dibukukan atau dikreasikan substansi tokoh yang ada dalam cerita. Hanya saja, buku yang dijadikan objek kajian dalam penelitian ini adalah buku kumpulan dongeng suku Mbojo yang masih berjenis klasik. Klasik di sini adalah cerita yang termuat dalam dongeng, bukan bentuknya. Jika sudah dibukukan barang tentu itu moderen. Pada umumnya dongeng memiliki unsur-unsur cerita yang melekat di dalamnya. Adapun unsurunsur dongeng ialah tokoh, alur cerita, latar, tema, moral, dan sudut pandang. Di bawah ini akan diuraikan dengan singkat, mendalam dan jelas mengenai unsur-unsur dongeng.

Tokoh menurut Nurgiyantoro (2016) adalah pelaku yang dikisahkan perjalanan hidupnya baik sebagai pelaku maupun sebagai penderita. Tokoh, berdasarkan perannya, dapat dibedakan menjadi dua, yaitu tokoh protagonis dan antagonis. Tokoh protagonis adalah tokoh yang mencerminkan perilaku baik, sementara tokoh antagonis adalah tokoh yang mencerminkan perilaku buruk (Lukens, 2003; Tarigan, 2013; Nurgiyantoro, 2016; Faidah, 2018). Tokoh-tokoh yang muncul dalam dongeng harus mencerminkan karakter-karakter yang melekat pada tokoh itu, sehingga pembaca atau pendengar dapat menangkap peran yang dimainkan oleh tokoh cerita. Tokoh memiliki peran atau fungsi masing-masing. Untuk memudahkan dalam pembagian peran atau fungsi maka Tarigan (2013) menawarkan tiga klasifikasi tokoh yaitu tokoh utama, tokoh penunjang dan tokoh latar belakang. Tokoh utama adalah tokoh yang mendominasi serangakaian cerita, baik dia hadie sebagai tokoh yang menang, kalah, senang maupun sedih. Tokoh penunjang adalah tokoh yang memainkan peranan yang tidak penting, biasanya timbul dan muncul begitu saja. Sementara tokoh latar belakang adalah tokoh yang melengkapi keserasia tempat dan suasana.

Untuk memudahkan pemahaman, alur cerita itu sama dengan plot. Plot memang sangat popular karena istilah ini diadopsi dari istilah luar. Namun demikian, baik plot maupun alur memiliki makna yang sama. Brooks dan Warren dalam Tarigan (2013) menyebutkan bahwa alur adalah struktur gerak atau laku dalam karya fiksi. Alur dalam dongeng biasanya alur mundur. Cara sederhana mengindentifikasi alur mundur dalam dongeng yaitu dengan frasa pada zaman dahulu, dahulu kala, pada suatu zaman,dan frasa lain yang menunjukan waktu lampau.Alur umumnya mengikuti pola unsur tradisional yang diperkenalkan Adelstein dan Pival (1976) meliputi: exposition, complication, rising action, turning point, and ending. Di sini akan diuraikan singkat unsur tradisional yang dikemukakan di atas yang memiliki keterkaitan dengan dongeng. Exposition yaitu pengenalan tokoh yang ada dalam cerita. Complication yaitu peristiwa awal yang memunculkan ketegangan seperti masalah dan kerusakan. Rising action yaitu memuncaknya 
masalah,. Turning point yaitu klimaks atau puncak uang mendebarkan dalam suatu cerita. Ending adalah akhir dari sebuah cerita. Latar sama dengan setting. Latar berkaitan dengan tempat di mana suatu kisah diceritakan. Menurut Nurgiyantoro (2016) latar meruapakan tempat atau lokasi di mana cerita itu terjadi, lingkungan sosial budaya, dan keadaan keadaan kehidupan masyarakat. Dalam dongeng, latar (tempat) umumnya dimunculkan seperti di gunung, di sawah, di laut, di suatu pedesaan dan lainya.

Tema ialah ide/gagasan yang mengikat seluruh rangkaian cerita (Lukens, 2003). Zainurrahman (2011) menyebut ide sebagai kerangka dasar pemandu tulisan. Sementara Tarigan (2013) menyebut tema sebagai gagasan utama atau pikiran pokok. Dalam dongeng tema biasanya hadir sebagai gagasan yang menyatu pada rangakaian cerita. Moral merupakan sebuatan lain dari amanat. Dalam dongeng untuk usia anak, istilah amanat sangatlah sesuai, karena sesuai dengan tingkat keterbacaan bahasa yang mereka miliki. Amanat itu dapat dimaknai sebagai pesan (Nurgiyantoro, 2016). Pesan yang ingin disamaikan penulis melalui cerita (dongeng) biasanya muncul sebagai pelajaran hidup. Sifat amanat haruslah mengandung nilai edukatif bagi pembaca atau pendengar. Nilai-nilai ini kemudian akan menjadi pesan kehidupan. Sudut pandang yaitu cara sebuah cerita dikisahkan, ditulisakan dan dibacakan (Nurgiyantoro, 2016). Selain itu, sudat pandang juga dapat dikatakan cara pandang. Cara pandang di sini dikaitkan dengan bagaaimana seorang pengarang menampilkan tokoh dalam cerita, menampilkan tindak tutur dalam cerita, latar dan berbagai peristiwa yang hidup dalam cerita.

Berbicara soal nilai pendidikan karakter sama halnya dengan berbicara mengenai pendidikan karakter itu sendiri. Sejatinya karakter dibentuk melalui tiga medium seperti keluarga, lingkungan sosial dan sekolah. Arwansyah, Suwandi, \& Widodo, (2017) dalam penelitiannya berjudul characther education values in The sarapan tradition folklore on writting skills learning menemukan tiga nilai pendidikan karakter dalam penelitian itu pertama nilai peduli sosial, kedua nilai pendidikan budaya dan ketiga nilai religius. Apa yang ditemukan oleh Arwansyah, Suwandi dan Widodo itu menegasikan hubungan nilai pendidikan karakter dengan tiga medium yang telah disebutkan di atas. Hal itu juga disebutkan oleh Ratna (2013) bahwa Peran karya sastra juga merupakan inti dari pendidikan karakter itu sendiri yang berfungsi untuk menanamkan rasa kebangsaan, kebanggaan, kepahlawanan, dan kesetiaan pada negara dan tanah air.

Pendidikan karakter menurut Lickona (1991) harus memuat tiga unsur pertama di antaranya moral knowing, moral feeling dan moral action. Elviana, Fakar, dan Bulan (2020), memahami apa yang disebut oleh Lickona tersebut sebagai pengetahuan perasaan dan tindakan. Karakter tidak hanya diketahui tapi harus dirasakan dan diamalkan. Junaini, Agustina, \& Canrhas (2017) mengemukakan bahwa internalisasi nilai pendidikan karakter yang efektif dan bermakna itu melalui pemahaman nilai karakter dan tindakan kebaikan. Dengan demikian, yang paling penting dari pendidikan karakter adalah tindakan-tindakan yang menuat unsur karakter. Ada 18 nilai yang harus menjadi rujukan utama karakter (Kemendikbud, 2011). Berikut ini akan diuraikan dalam tabel nilai-nilai karakter.

Tabel 1. Nilai-nilai karakter

\begin{tabular}{ll}
\hline Nilai Karakter & Uraian \\
\hline Religius & $\begin{array}{l}\text { Sikap dan perilaku yang patuh dalam melaksanakan ajaran agama } \\
\text { yang dianutnya, toleran terhadap pelaksanaan ibadah agama lain, dan } \\
\text { hidup rukun dengan pemeluk agama lain. }\end{array}$ \\
\hline Jujur & $\begin{array}{l}\text { Perilaku yang didasarkan pada upaya menjadikan dirinya sebagai } \\
\text { orang yang selalu dapat dipercaya dalam perkataan, tindakan, dan } \\
\text { pekerjaan. }\end{array}$ \\
\hline Toleransi & Sikap dan tindakan yang menghargai perbedaan agama, suku, etnis, \\
\hline
\end{tabular}


pendapat, sikap, dan tindakan orang lain yang berbeda dari dirinya.

\begin{tabular}{|c|c|}
\hline Disiplin & $\begin{array}{l}\text { Tindakan yang menunjukkan perilaku tertib dan patuh pada berbagai } \\
\text { ketentuan dan peraturan }\end{array}$ \\
\hline Kerja keras & $\begin{array}{l}\text { Tindakan yang menunjukkan perilaku tertib dan patuh pada berbagai } \\
\text { ketentuan dan peraturan }\end{array}$ \\
\hline Kreatif & $\begin{array}{l}\text { Berpikir dan melakukan sesuatu untuk menghasilkan cara atau hasil } \\
\text { baru dari sesuatu yang telah dimiliki. }\end{array}$ \\
\hline Mandiri & $\begin{array}{l}\text { Sikap dan perilaku yang tidak mudah tergantung pada orang lain } \\
\text { dalam menyelesaikan tugas-tugas }\end{array}$ \\
\hline Demokratis & $\begin{array}{l}\text { Cara berfikir, bersikap, dan bertindak yang menilai sama hak dan } \\
\text { kewajiban dirinya dan orang lain }\end{array}$ \\
\hline Rasa ingin tahu & $\begin{array}{l}\text { Sikap dan tindakan yang selalu berupaya untuk mengetahui lebih } \\
\text { mendalam dan meluas dari sesuatu yang dipelajarinya, dilihat, dan } \\
\text { didengar }\end{array}$ \\
\hline Semangat kebangsaan & $\begin{array}{l}\text { Cara berpikir, bertindak, dan berwawasan yang menempatkan } \\
\text { kepentingan bangsa dan negara di atas kepentingan diri dan } \\
\text { kelompoknya }\end{array}$ \\
\hline Cinta tanah air & $\begin{array}{l}\text { Cara berpikir, bertindak, dan berwawasan yang menempatkan } \\
\text { kepentingan bangsa dan negara di atas kepentingan diri dan } \\
\text { kelompoknya. }\end{array}$ \\
\hline Menghargai pr & $\begin{array}{l}\text { Sikap dan tindakan yang mendorong dirinya untuk menghasilkan } \\
\text { sesuatu yang berguna bagi masyarakat, dan mengakui, serta } \\
\text { menghormati keberhasilan orang lain. }\end{array}$ \\
\hline Bersahabat/komunikatif & $\begin{array}{l}\text { Sikap dan tindakan yang mendorong dirinya untuk menghasilkan } \\
\text { sesuatu yang berguna bagi masyarakat, dan mengakui, serta } \\
\text { menghormati keberhasilan orang lain. }\end{array}$ \\
\hline Cinta damai & $\begin{array}{l}\text { Sikap dan tindakan yang mendorong dirinya untuk menghasilkan } \\
\text { sesuatu yang berguna bagi masyarakat, dan mengakui, serta } \\
\text { menghormati keberhasilan orang lain }\end{array}$ \\
\hline Gemar membaca & $\begin{array}{l}\text { Kebiasaan menyediakan waktu untuk membaca berbagai bacaan yang } \\
\text { memberikan kebajikan bagi dirinya }\end{array}$ \\
\hline Peduli lingkungan & $\begin{array}{l}\text { Sikap dan tindakan yang selalu berupaya mencegah kerusakan pada } \\
\text { lingkungan alam di sekitarnya, dan mengembangkan upaya-upaya } \\
\text { untuk memperbaiki kerusakan alam yang sudah terjadi. }\end{array}$ \\
\hline Peduli social & $\begin{array}{l}\text { Sikap dan tindakan yang selalu ingin memberi bantuan pada orang } \\
\text { lain dan masyarakat yang membutuhkan }\end{array}$ \\
\hline Tanggung jawab & $\begin{array}{l}\text { Sikap dan perilaku seseorang untuk melaksanakan tugas dan } \\
\text { kewajibannya, yang seharusnya dia lakukan, terhadap diri sendiri, } \\
\text { masyarakat, lingkungan (alam, sosial dan budaya), negara dan Tuhan } \\
\text { Yang Maha Esa }\end{array}$ \\
\hline
\end{tabular}

(Diambil dai pedoman pelaksanaan pendidikan karakter Kemendikbud, 2011)

Nurfalah (2016) menawarkan penanaman nilai pendidikan karakter sedari dini kepada anak, dengan demikian diharapkan ada pembentukan karakter. Karakter, jika dilihat dar tiga medium yang telah disebutkan di atas maka membentuk tiga siklus yaitu keluar, lingkungan dan sekolah. Pembentukan marakter memang dirasa efektif jika ditanamkan melalui keluarga. Cara penanamannya juga beragam bergantung kepada konsensus keluarga tersebut, baik melalui tingkah laku, ucapan, maupun melalui cara membacakan dengeng sebelum tidur kepada anak-anak. Nurgiyantoro (2016) menyebutkan bahwa membacakan dongeng kepada anak-anak sebelum tidur akan memberikan efek baik bagi anak. Anak dapat mengingat tokoh-tokoh yang disebutkan, peran tokoh dan tempat di mana cerita itu terjadi. 
Analisis maupun penelitian tentang dongeng suku Mbojo masih sangat jarang ditemukan. Berdasarkan pada uraian di atas terdapat banyak keterkaitan antara nilai pendidikan dan dongeng yang melakat pada suatu daerah. Dengan dimikian, penelitian ini bertujuan untuk mendeskripsikan nilai-nilai pendidikan karakter yang termuat dalam dongeng suku Mbojo.

\section{METODE PENELITIAN}

Penelitian ini yaitu metode deskriptif kualitatif. Data penelitian diambil dari buku "kumpulan dongeng suku Mbojo: sebagai bahan ajar bahasa Indonesia di Sekolah Dasar" yang diterbitkan oleh penerbit Nathan Indonesia 2020. Instrumen yang digunakan dalam penelitian ini adalah peneliti sendiri (human instrument). Data-data yang dibutuhkan dalam penelitian dikumpulkan melalui membaca secara cermat unsur-unsur dongeng yang termuat dalam buku. Teknik yang digunanakan dalam penelitian teknik catat. Teknik analisis data yang dilakukan dalam penelitian ini yaitu menggunakan teknik analisis isi (content analysis). Dalam penelitian ini yang menjadi unit analisis adalah semua judul dongeng yang termuat dalam buku kumpulan dongeng suku Mbojo.

\section{HASIL DAN PEMBAHASAN}

\section{A. Hasil Penelitian}

\section{Nilai-nilai Pendidikan Karakter dalam Dongeng Suku Mbojo}

Pada penelitian ini, telah dilakukan pengumpulan data pada buku kumpulan dongeng suku Mbojo. Ada beberapa judul dongeng yang dipilih dan analisis. Judul-judul tersebut antara lain uta bangkolo, meletusnya gunung tambora, menta dea, asal usul pulau ular, dan la koka. Penentuan nilai pendidikan karakter didasarkan pada analisis mendalam mengenai isi cerita baik itu secara eksplisit maupun implisit. Berdasarkan teknik pencatatan yang dilakukan oleh peneliti, ditemukan berbagai muatan nilai pendidikan karakter dalam dongeng suku mbojo. Di bawah ini akan ditunjukan dalam tabel 2 nilai-nilai pendidikan karakter yang ditemukan.

Tabel. 2. Sebaran muatan nilai karakter dalam buku dongeng suku Mbojo

\begin{tabular}{lll}
\hline No & \multicolumn{1}{c}{ Judul Dongeng } & \multicolumn{1}{c}{ Nilai Pendidikan Karakter } \\
\hline 1 & Uta bangkolo & Peduli sosial \\
\hline 2 & Meletusnya gunung tambora & Keadilan \\
\hline 3 & Menta dea & Tanggung jawab \\
\hline 4 & Asal usul pulau ular & Kerjasama, \\
\hline 5 & La koka & Menghargai pendapat orang lain \\
\hline
\end{tabular}

Berdasarkan tabel di atas, terdapat 5 nilai pendidikan karakter yang tersebar pada 5 dongeng yang dianalisis. Nilai-nilai tersebut antara lain peduli sosial, keadilan, tanggung jawab, kerjasama dan menhargai pendapat orang lain. Adapun kelima nilai tersebut akan dibahas pada sub bab pembahasan.

\section{B. Pembahasan}

\section{Nilai Peduli Sosial}

Nilai peduli sosial termasuk dalam nilai pendidikan karakter yang termaktub dalan buku pedoman pendidikan karakter oleh Kemendikbud. Nilai peduli sosial yang muncul dalam dongeng suku Mbojo yang berjudul "Uta Bangkolo". terdapat dalam penggalan teks "Tiba-tiba, di tengah laut, kapal yang mereka naiki bocor dan tenggelam. Karena berdada di tengah laut Ncuhi dan rakyatnya sudah tidak sanggup lagi berenang, mereka berpasrah diri menunggu maut menjemput. Namun 
takdir berkata lain, bukannya maut menjemput mereka, melainkan ikan. Ikan-ikan datang bergerombolan. Ada yang berukuran besar da nada juga berukuran kecil. Ikan itu bernama ikan ekor kuning, dalam bahasa Bima disebut Uta Bangkolo. Ikan-ikan tesebut datang menolong Ncuhi dan warganya dengan mendorongnya hingga pinggir pantai".

Berdasarkan penggalan cerita di atas terdapat teks yang menyebutkan secara ekspilist bahwa ikan-ikan tersebut datang menolong Ncuhi dan warganya. Menolong memiliki kesamaan arti dengan membantu. Sementara itu, peduli sosial menurut Kemendikbud, (2011) Sikap dan tindakan yang selalu ingin memberi bantuan pada orang lain dan masyarakat yang membutuhkan. Apa yang dilakukan oleh Uta Bangkolo ialah termasuk dalam nilai pendidikan karakter.

\section{Nilai Keadilan}

Nilai keadilan termasuk dalam nilai pendidikan karakter yang termaktub dalan buku pedoman pendidikan karakter oleh Kemendikbud. Nilai keadilan yang muncul dalam dongeng suku Mbojo yang berjudul "Meletusnya Gunung tambora". terdapat dalam penggalan teks "Di Desa Tambora, terdapat sebuah kerajaan yang dipimpin oleh sang raja. Raja itu terkenal dengan keangkuhan, kesombongan dan kezalimannya. Karena sifat buruknya itu, sang rajapun tidak disukai oleh rakyatnya. Pada suatu ketika, dia memerintahkan kepada pengawal kerajaan untuk mengambil hasil panen dari rakyat yang sebagian besar adalah petani. Padahal, saat itu sedang masa paceklik sehingga hasil panen sedikit dan tidak mencukupi kebutuhan petani sendiri".

Berdasarkan penggalan cerita di atas, terdapat antonim yang muncul dengan menunjukan bahwa raja terkenal dengan zalim, sombong dan tidak adil. Seharusnya raja itu harus memiliki sikap adil. Menurut Junaini, Agustina, dan Canrhas (2017) bahwa sikap adil termasuk dalam nilai pendidikan karakter.

\section{Nilai Tanggung Jawab}

Nilai tanggung jawab termasuk dalam nilai pendidikan karakter yang termaktub dalan buku pedoman pendidikan karakter oleh Kemendikbud. Nilai tanggung jawab yang muncul dalam dongeng suku Mbojo yang berjudul "Menta Dea". terdapat dalam penggalan teks "berita itu akhirnya sampai ke telinga seorang kesatria tangguh nan baik hati bernama Menta Dea. Mendengar berita itu awalnya menta dea tidak percaya, namun ketika melihat sendiri ular raksasa melilit kerbau dan menelannya. Barulah ia percaya akan berita yang selama ini didengarnya. Menta Dea menantang ular raksasa itu bertarung. Terjadilah pertarungan hebat antara menta dea dengan ular raksasa. Akhirnya ular raksasa itu berhasil dikalahkan oleh menta dea".

Berdasar penggalan cerita di atas. menta dea memperlihatkan sikap dan tanggung jawab sebagai kesatria dengan cara mengambil peran untuk mengalahkan ular raksasa. Sementara itu, Kemendikbud (2011) menyebut bahwa nilai pendidikan karakter tanggung jawab sebagai Sikap dan perilaku seseorang untuk melaksanakan tugas dan kewajibannya, yang seharusnya dia lakukan, terhadap diri sendiri, masyarakat, lingkungan (alam, sosial dan budaya), negara dan Tuhan Yang Maha Esa. Berdasarkan nilai pendidikan karakter yang disebutkan oleh Kemendikbud di atas, dapat dianalisis bahwa apa yang dilakukan oleh menta dea merupakan sebuah sikap melakat pada dirinya sebagai kesatria. Sehingga, ia berkewajiban dalam menolong masyarakat di daerahnya yang sedang dalam cengkaraman bahaya dan gangguan ular raksasa itu.

\section{Nilai Kerjasama}

Nilai kerjasama termasuk dalam nilai pendidikan karakter seperti yang tertuang dalam buku berjudl model pendidikan karakter kayra Zuchdi, Prasetya, dan Masruri (2013). Nilai kerjasama yang muncul dalam dongeng suku Mbojo yang berjudul "Asal-usul Pulau Ular", terdapat dalam 
penggalan teks "mengetahui istrinya diculik, kepala suku kemudian mengarahkan warganya untuk menemukan dan menyelamatkan sang istri. Dengan usaha gotong royong akhirnya mereka menemkan istri kepala suku dalam keadaan luka parah".

Nilai kerjasama yang didapatkan dalam judul dongeng asal usul pulau ular terlihat dalam penggalan usaha gotong royong. Gotong royong dapat diartikan sebagai sikap bekerjasama dalam mengerjakan sesuatu atau memecahkan masalah bersama.

\section{Nilai Menghargai Pendapat Orang Lain}

Nilai tanggung jawab termasuk dalam nilai pendidikan karakter. Nilai tanggung jawab yang muncul dalam dongeng suku Mbojo yang berjudul "La Koka", terdapat dalam penggalan teks "orang-orang berteriak mengingatkan La Koka agar tidak melakukan itu. Mereka khawatir akan keselamatan La Koka. Namun La Koka tidak menghiraukan teriakan itu. Kesombongan telah menyelimuti diri La Koka".

Berdasar pada penggalan cerita di atas, seharusnya La Koka mendengarkan pendapat dari warga agar ia tidak melompat, namun ia melakukannya. Menghargai pendapat orang lain itu sangat perlu karena bisa jadi pendapat orang lainlah yang benar. Sari (2017) mengungkapkan dalam penelitiannya bahwa, menghargai pendapat orang lain merupakan tindakan seseorang yang mau menghargai pemikiran atau keinginan orang lain serta mampu menerima pendapat yang diberikan orang lain.

\section{SIMPULAN DAN SARAN}

\section{A. Simpulan}

Berdasarkan hasil penelitian ini dapat disimpulkan bahwa ada banyak nilai pendidikan karaktek yang terdapat dari dongeng suku Mbojo. Nilai pendidikan karakter ini menjadi pedoman hidup bagi masyarakat suku Mbojo. Nilai-nilai pendidikan karakter itu seperti; nilai peduli sosial, keadilan, tanggung jawab, kerjasama, dan menghargai pendapat orang lain.

\section{B. Saran}

Berdasarkan simpulan dari penelitian ini. Maka ada satu saran penting terkait keberlanjutan penelitian lanjutan. Dalam dongeng suku Mbojo masih terdapat unsur-unsur dongeng yang perlu dikaji salah satunya amanat-amanat yang terkandung dalam dongeng. Maka peneliti menyarankan kepada peneliti lain untuk meneliti hal yang disebut di atas.

\section{DAFTAR RUJUKAN}

Adelstein, M. E., \& Pival, J. G. 1976. The Writing Comitment. New York: Harcourt Brace Javanovich, Inc.

Arwansyah, Y., Suwandi, S., \& Widodo, S. 2017. Characther Education Values in The Sarapan Tradition Folklore on Writting Skills Learning. Komposisi: Jurnal Pendidikan Bahasa, Sastra, Dan Seni, 18(1), 51-65.

Elviana, F., Fakar, A., \& Bulan, A. 2020. Pendidikan Karakter dan Pengajaran dengan Metode Demonstrasi untuk Kemajuan Belajar Generasi Millenial. Prosiding Seminar Nasional IPPeMas 2020, 1(1), 702-706. Sumbawa: LPPM Universitas Samawa.

Faidah, C. N. 2018. Dekonstruksi Sastra Anak: Mengubah Paradigma Kekerasan dan Seksualitas pada Karya Sastra Anak Indonesia. Jurnal Kredo, 2(1), 126-139.

Junaini, E., Agustina, E., \& Canrhas, A. 2017. Analisis Nilai Pendidikan Karakter Pada Cerita Rakyat Seluma. Jurnal Korpus, 1(1), 39-43. 
Kemendikbud. 2011. Pedoman Pelaksanaan Pendidikan Karakter. Jakarta: Pusat Kurikulum Kemendikbud RI.

Lickona, T. 1991. Educating for Character: how school can teach respect and responsibility. New York: Bantam Books.

Lukens, R. J. 2003. A Critical Handbook of Children's Literature. New York: Longman.

Nurfalah, Y. 2016. Urgensi Nilai-Nilai Karakter Pendidikan Karakter. Jurnal Pemikiran Islam, 27(1), 170-187.

Nurgiyantoro, B. 2016. Sastra Anak: Pengantar Pemahaman Dunia Anak (4th ed.). Yogyakarta: Gadjah Mada University Press.

Ratna, N. K. 2013. Peranan Karya Sastra, Seni, dan Budaya dalam Pendidikan Karakter. Yogyakarta: Pustaka Pelajar.

Sari, E.K. 2017. Peningkatan Sikap Menghargai Pendapat dan Prestasi Belajar Siswa Materi Menghargai Keputusan Bersama Melalui VCT Gejala Kontinum Di Kelas V SD Negeri 2 Karang Tengah. Skripsi. Tidak Diterbitkan. Universitas Muhammadiyah Purwokerto.

Setiawan, A., Suwandi, S., \& Slamet, S. . 2017. Caracter Education Values in Pacitan Folklore. Komposisi: Jurnal Pendidikan Bahasa, Sastra, Dan Seni, 18(1), 90-106.

Tarigan, H. G. 2013. Menulis sebagai Suatu Keterampilan Berbahasa. Bandung: Angkasa Bandung.

Zainurrahman. 2011. Menulis dari Teori hingga Praktik (Penawar Racun Plagiarisme). Bandung: Alfabeta.

Zuchdi, D., Prasetya, K.J. \& Masruri, S.M. 2013. Model Pendidikan Karakter. Yogyakarta: Multi Persindo. 